\title{
Description of the previously unknown male of Caligus mortis Kensley, 1970 (Copepoda: Caligidae), parasite of intertidal fish from South Africa
}

\author{
Nico J. Grobler ${ }^{1}$, Jo G. Van As ${ }^{1}$ and Piet A.S. Olivier ${ }^{2}$ \\ ${ }^{1}$ Department of Zoology and Entomology, University of the Free State, P.O. Box 339, Bloemfontein, 9300, South Africa; \\ ${ }^{2}$ School of Molecular and Life Sciences, University of the North, Private Bag X1106, Sovenga, 0727, South Africa
}

Key words: Copepoda, Caligidae, Caligus mortis, South Africa, intertidal fish

\begin{abstract}
Caligus mortis Kensley, 1970 was originally described from females collected from intertidal pools along the coast of Namibia. During surveys at Jeffreys Bay and De Hoop Nature Reserve in South Africa, both females and males of C. mortis were collected from intertidal pool fish hosts. Based on this material a full description of the male is given, and a comparison with the female reveals the sexual dimorphic characteristics.
\end{abstract}

The genus Caligus Müller, 1785 comprises numerous species, but the lack of an up-to-date revision of this genus makes taxonomic work difficult. The synopsis of the genus Caligus published by Margolis et al. (1975) bring the total of species described until 1975 to 208, of which 39 have been recorded off the coast of Africa. Since the synopsis was published, at least 38 descriptions of new nominal species were published. Kensley (1970) described the female of Caligus mortis Kensley, 1970 from intertidal rock pools at Rocky Point and Torra Bay, Namibia. Dojiri (1989) redescribed the species based on the holotype and other specimens from the collection of the South African Museum. The male of $C$. mortis has remained hitherto unrecorded. During fish parasitological surveys carried out in March and April of 1997, 1998 and 1999 at Jeffreys Bay and De Hoop Nature Reserve on the south coast of South Africa, specimens of $C$. mortis were found on three different resident intertidal fish species. Based on this material a full description of the male is given, and a comparison with the female reveals the sexual dimorphic characteristics. All comparisons with the female are based on the excellent redescription by Dojiri (1989).

\section{MATERIALS AND METHODS}

Fishes were collected with hand nets in intertidal pools. Caligid copepods were removed from the hosts and fixed in $70 \%$ ethanol. All preserved specimens were cleared in $85 \%$ lactic acid for at least $24 \mathrm{~h}$ before measurements were taken. The specimens were then dissected according to the wooden slide procedure of Humes and Gooding (1964). All drawings were made with the aid of a drawing tube. Specimens for scanning electron microscopy were dehydrated to absolute ethanol, critical-point dried, sputter coated with gold and studied in a JEOL WinSEM JSM 6400 at $10 \mathrm{kV}$. Mean body measurements are given in millimetres, followed by the range in parentheses. Measurements of appendages are given in micrometres.

\section{RESULTS}

Caligus mortis Kensley, 1970

Adult male

Figs. 1-23

Description: Body typically caligiform (Fig. 1). Total length of male (excluding setae on caudal rami) $1.88 \mathrm{~mm}(1.66-1.93 ; \mathrm{n}=5)$. Adult male much smaller than female. Cephalothorax suborbicular, less than 1.1 times wider than long. Frontal plates well developed; lunules large. Posterior sinuses deep; lateral zones not reaching fourth pediger; posterolateral corner of lateral zone with conspicuous sensory pit. Tip of antennule not reaching lateral limit of dorsal shield. Fourth pediger wider than long, distinctly separated from genital complex. Genital complex (Fig. 2) with slightly rounded posterolateral corners. Abdomen (Fig. 2) one-segmented, wider than long. Caudal rami longer than wide, shorter than abdomen. Posterior margin of each ramus armed with two outer, one small, medial and three large terminal plumose setae (Figs. 2, 21).

Antennule two-segmented (Fig. 3); proximal segment trapezoid, much broader than distal segment, with 14 large, stout, marginal setae, 13 short, plumose ventral setae and two short, plumose dorsal setae (Fig. 4); distal segment rod-shaped, much longer than wide, armed with 13 terminal setae and one subterminal seta on posterior margin. Antenna three-segmented (Fig. 5); proximal segment unarmed; second segment large, robust, armed with two corrugated patches; terminal segment smallest; claw bifid (Fig. 16); strong seta on each side of claw, close to base. Postantennary process hook-like (Fig. 6) with two basal papillae, bearing one 

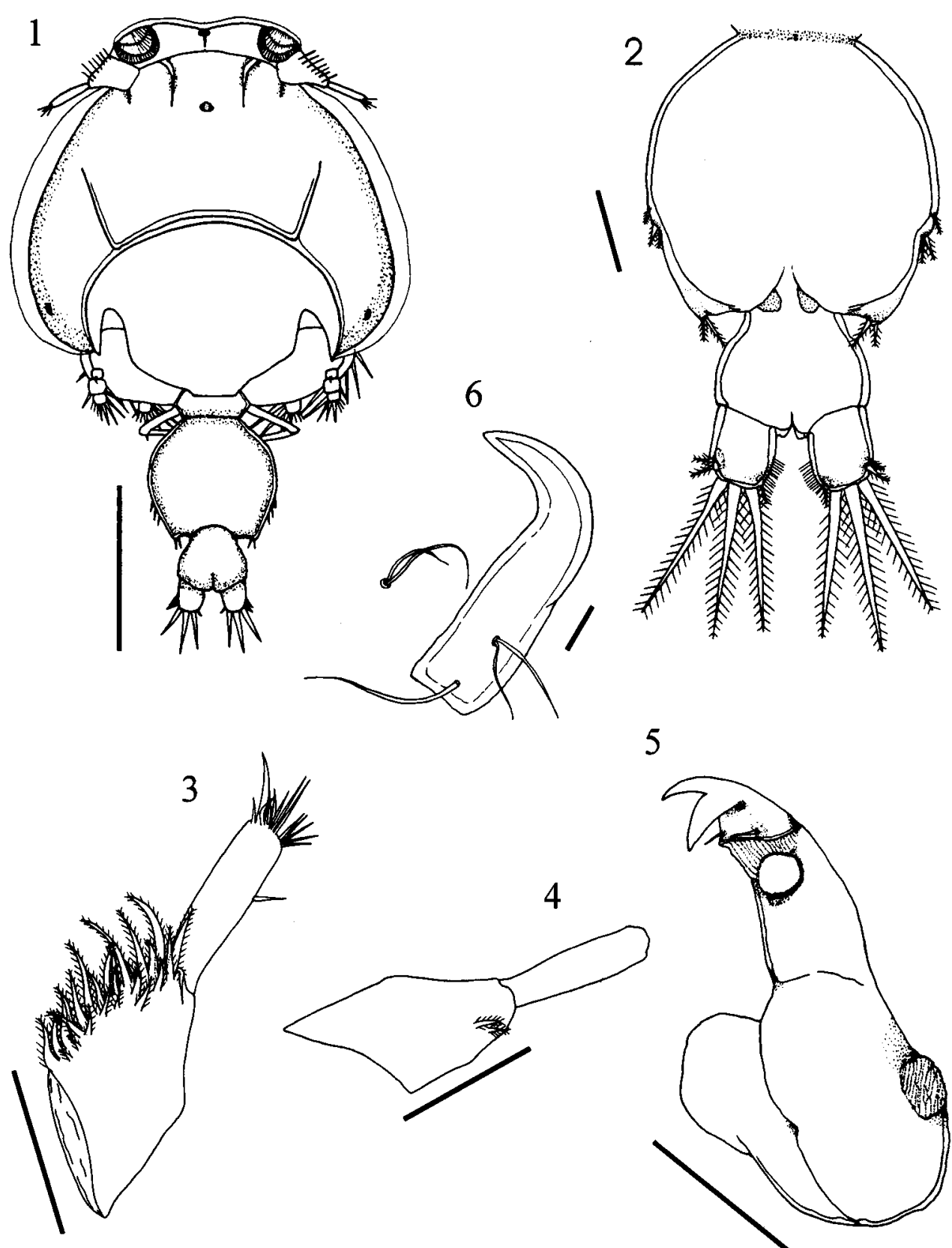

5

Figs. 1-6. Microscope projection drawings of a male Caligus mortis Kensley, 1970. Fig. 1. Dorsal view. Fig. 2. Urosome. Fig. 3. process. Scale bars: Fig. $1=500 \mu \mathrm{m}$; Figs. $2-5=100 \mu \mathrm{m}$; Fig. $6=10 \mu \mathrm{m}$.

and two long setules respectively and one similar papilla located nearby on sternum bearing two long setules.

Mouth tube longer than wide (Fig. 17). Mandible (Fig. 7) with 12 teeth on mediodistal margin. Maxillule dentiform (Fig. 8), sharply hook-like with papilla bearing three setae; small band of striations on middle of process. Maxilla two-segmented, brachiform (Fig. 9); proximal segment (lacertus) unarmed; distal segment (brachium) slender with flabellum on medial margin bearing hyaline membrane; calamus with three rows of tiny spinules; canna with two rows of tiny spinules, shorter than calamus. Maxilliped three-segmented (Fig. 10); proximal segment stout, unarmed; second and terminal segments fused, forming strong claw; second segment with small, hyaline, setiform process in small pit and one naked seta on inner distal corner; terminal segment with minute accessory tooth near inner distal end. Sternal furca with small base (Figs. 11, 18); tines not tapered, curving inward, slightly flared, and truncate at tip. 

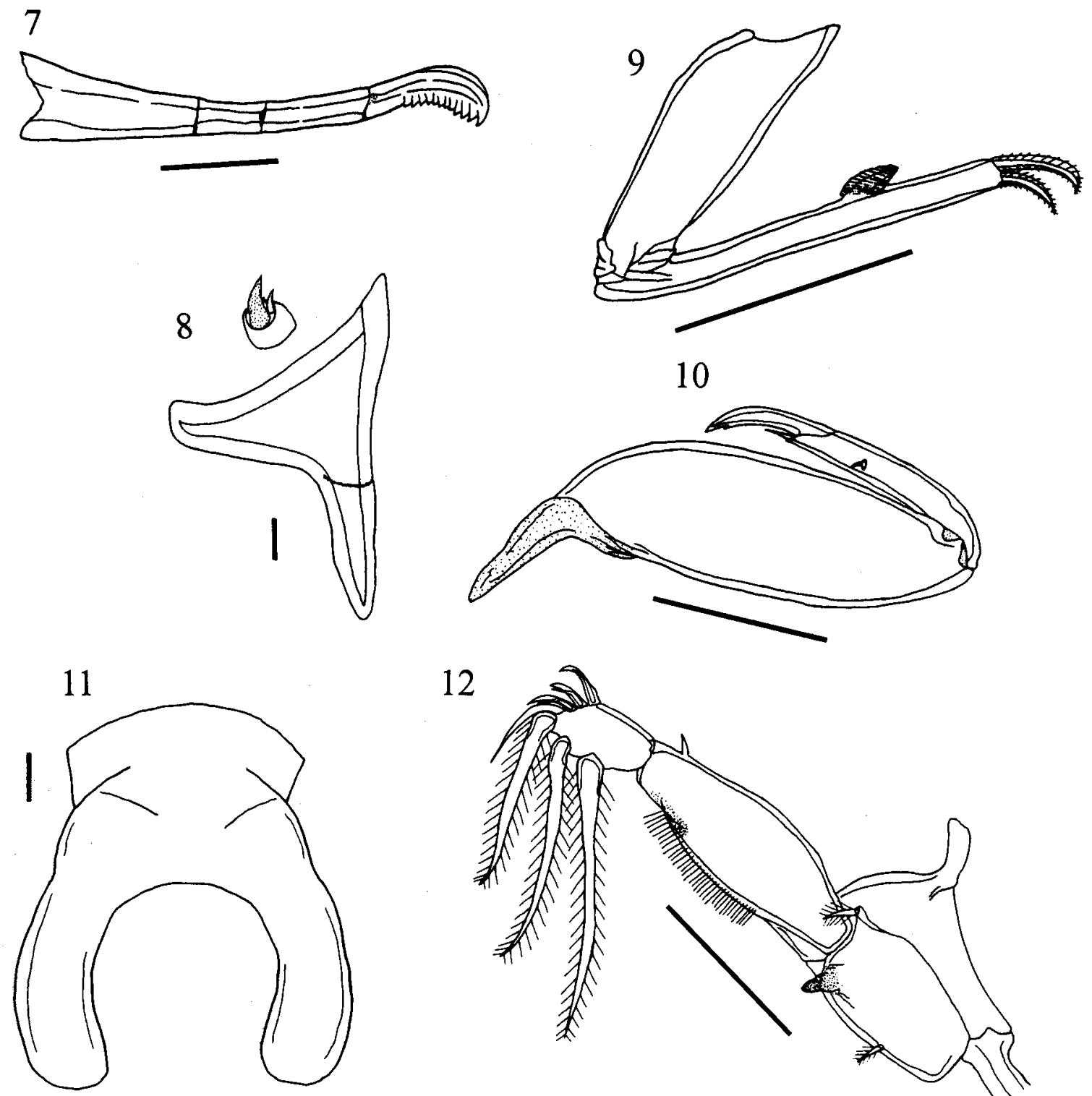

12

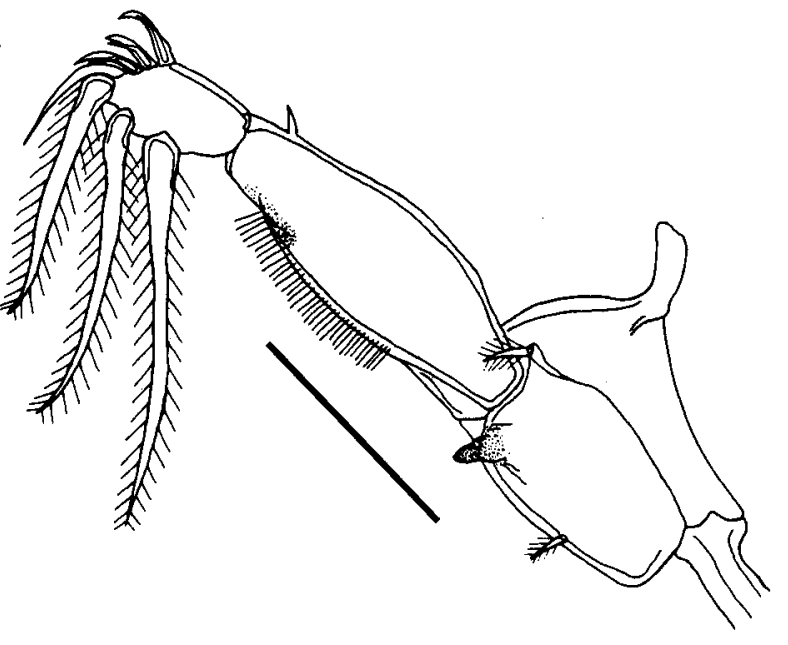

Figs. 7-12. Microscope projection drawings of a male Caligus mortis Kensley, 1970. Fig. 7. Mandible. Fig. 8. Maxillule. Fig. 9. Maxilla. Fig. 10. Maxilliped. Fig. 11. Sternal furca. Fig. 12. Leg 1. Scale bars: Figs. 7, 9, 10, $12=100 \mu \mathrm{m} ;$ Figs. $8,11=10 \mu \mathrm{m}$.

Leg 1 biramous (Fig. 12); protopod with one inner and one outer short, plumose seta; exopod twosegmented; first segment with lateral distal spine and medial row of setules; second segment with four terminal elements; first spine simple and slightly longer than spines 2 or 3 ; spines 2 and 3 with spiniform secondary process, equaling the length of spines (Fig. 19); spine 4 two times as long as spine 1 , robust, tapering and unarmed; three long, plumose setae on posterior margin of same segment, different in size; endopod rudimentary, unarmed. Leg 2 coxa with large plumose seta and one setule near intercoxal plate (Fig. 13); basis with one long medial setule and striated membrane along medial margin, and one setule on anterolateral margin; exopod three-segmented; first segment with one outer slightly curved spine and one long, plumose inner seta; second segment with one outer spine and one long, plumose inner seta; both spines with serrated membranes along distal two-thirds of outer and inner margins; third segment with three spines on anterolateral margin (first spine minute; second spine with hyaline membrane and row of hairs on inner margin; third spine with striated membrane along outer margin and setules on inner margin) and five long, plumose setae; endopod three-segmented; first segment with one long, plumose inner seta; second segment with two long, plumose inner setae and a crest of prominent hairs on outer margin; third segment with six long, plumose terminal setae and patch of hairs on outer margin. Leg 3 with small adhesive pad on 

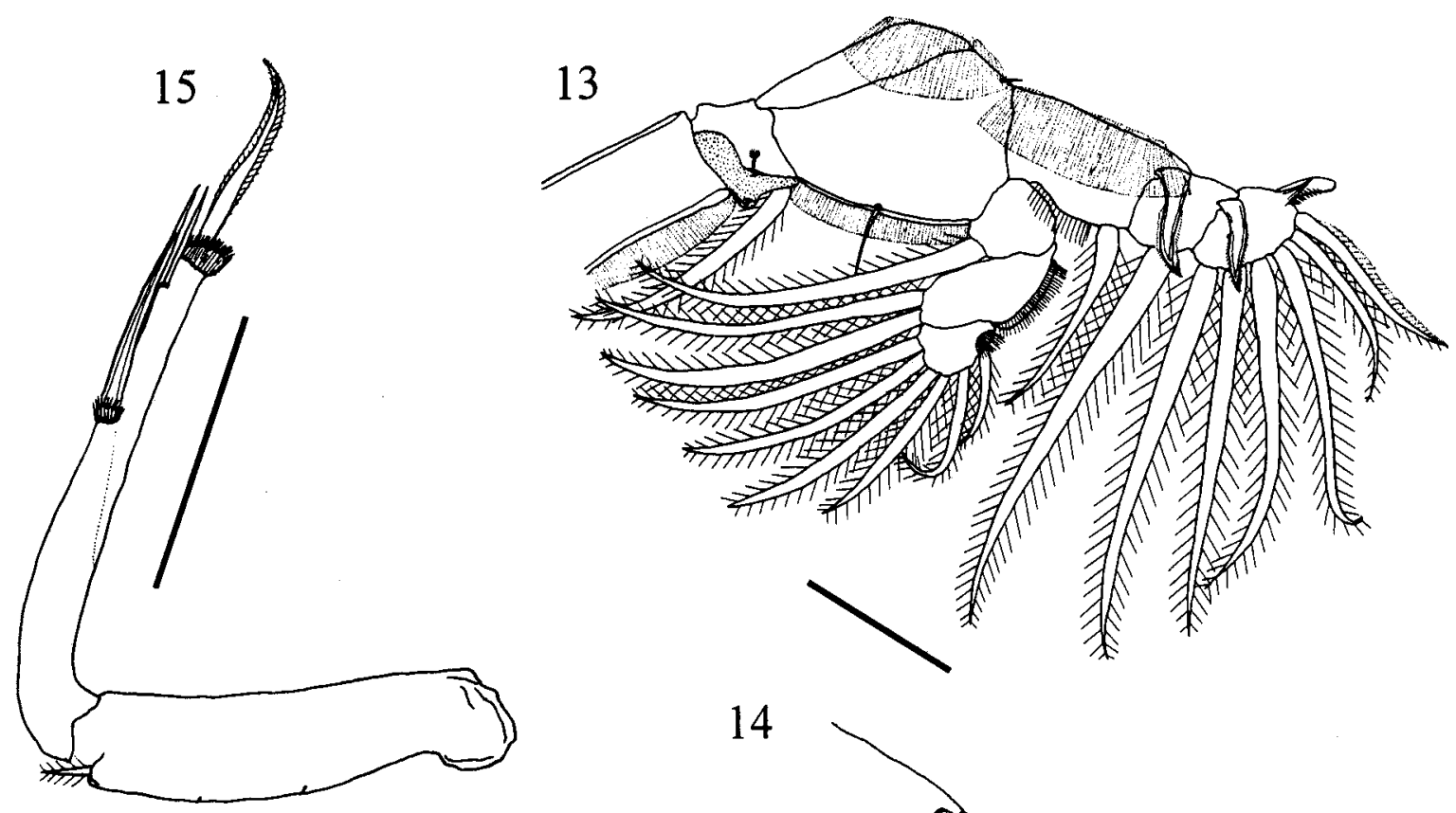

14

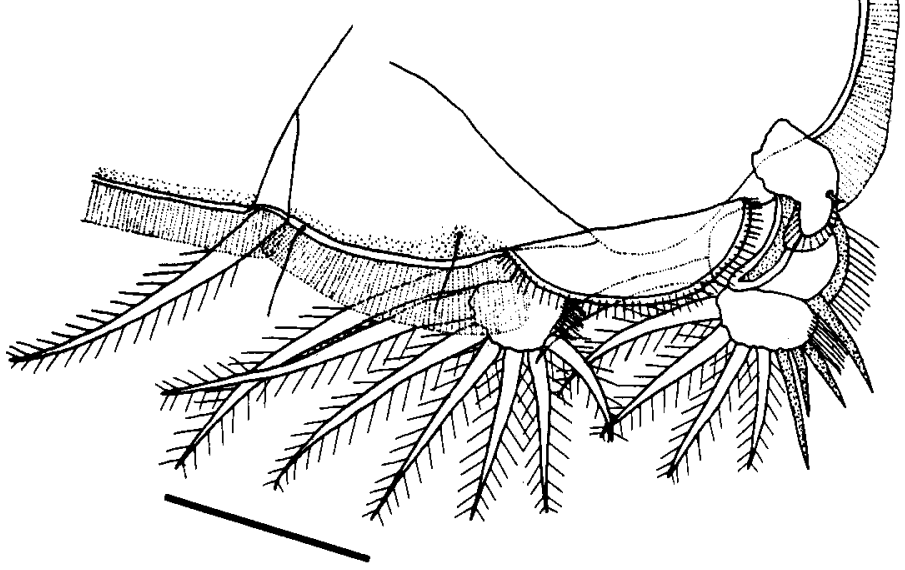

Figs. 13-15. Microscope projection drawings of a male Caligus mortis Kensley, 1970. Fig. 13. Leg 2. Fig. 14. Leg 3 . Fig. 15. Leg 4. Scale bars: Figs. 13-15 $=100 \mu \mathrm{m}$.

ventrolateral surface and striated marginal membranes (Fig. 14); exopod three-segmented; first segment with large basal claw-like spine situated subterminally on basal swelling which bears terminal striated membrane and lateral setule; second segment with one outer spine and one plumose inner seta; third segment with three spines of different lengths and four plumose setae of equal length; both segments with rows of setules on lateral margins; endopod two-segmented; first segment expanded laterally into velum on outer margin and bearing one long, plumose seta on medial margin; second segment with five long, plumose setae of different lengths and rows of hair on lateral margin. Leg 4 protopod bearing two setules (Fig. 15); outer seta on protopod short and plumose; long and slender exopod, indistinctly two-segmented; first segment with spine, almost as long as terminal spine, naked and bearing pectinate membrane at base; second segment with two spines of different size; first spine relatively short, naked, not highly sclerotised, without pectinate membrane; terminal spine with two rows of serrated membranes and equipped with pectinate membrane at base. Leg 5 rudimentary (Figs. 2, 20), on lateral margin of genital complex, represented by three plumose setae. Leg 6 rudimentary (Fig. 2), on rounded posterolateral corner of genital complex, represented by two plumose setae. 

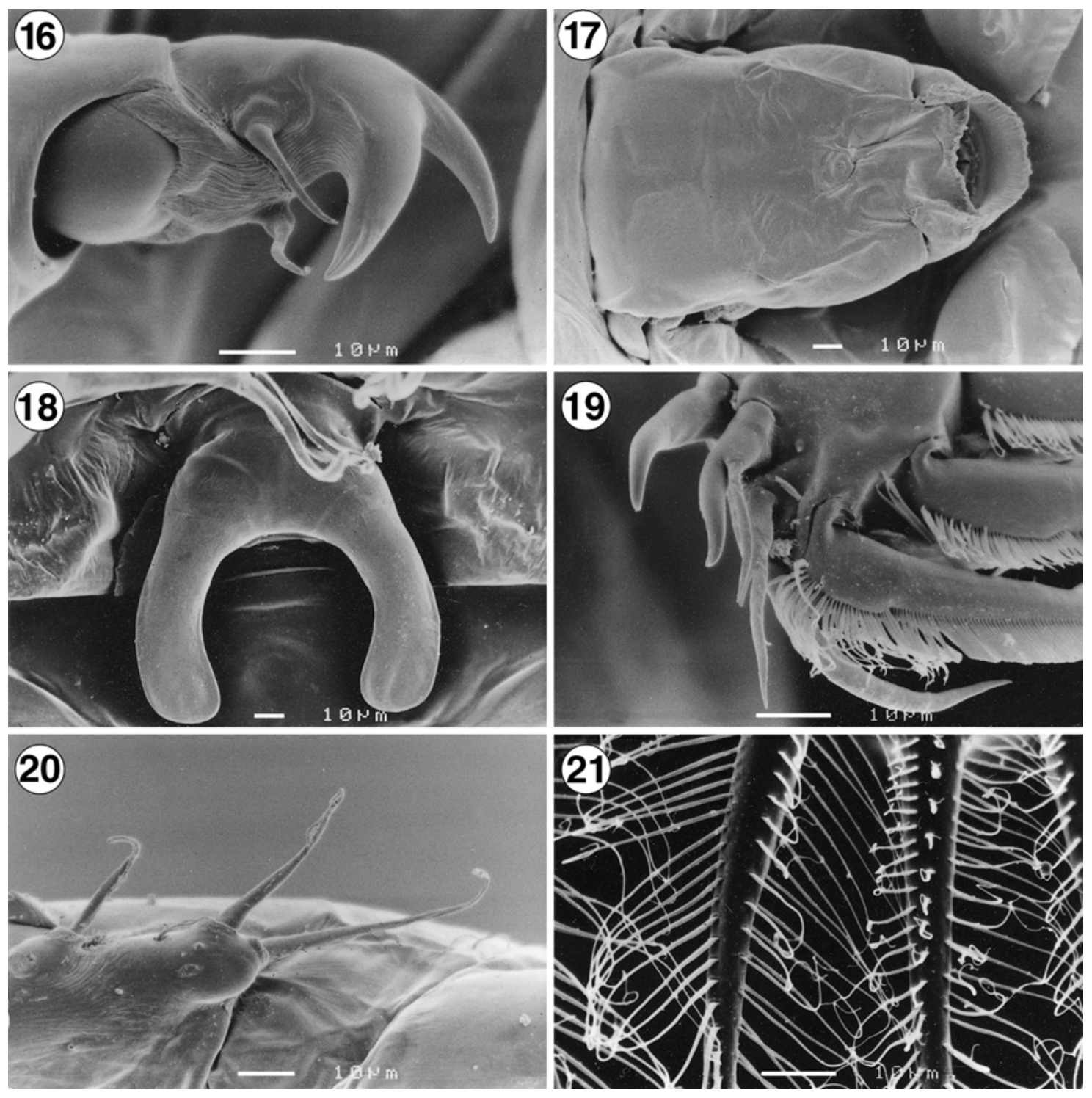

Figs. 16-21. Scanning electron micrographs of a male Caligus mortis Kensley, 1970. Fig. 16. Bifid claw of antenna. Fig. 17. Mouth tube. Fig. 18. Sternal furca. Fig. 19. Tip of leg 1 exopod showing spines 2 and 3 with spiniform secondary process. Fig. 20. Leg 5. Fig. 21. Plumose setae on caudal ramus. Scale bars: Figs. $16-21=10 \mu \mathrm{m}$.

Armature on rami of legs 1-4:

$\begin{array}{lll}\text { Leg 1 } & \text { Exp 1-0; III, 1, 3 } & \text { Enp (rudimentary) } \\ \text { Leg 2 } & \text { Exp I-1; I-1; I, II, 5 } & \text { Enp 0-1;0-2; 6 } \\ \text { Leg 3 } & \text { Exp I-0; 1-1; 3, 4 } & \text { Enp 0-1;6 } \\ \text { Leg 4 } & \text { Exp I-0; I, I } & \text { Enp (absent) }\end{array}$

$\mathrm{M}$ a t e r i a 1 e $\mathrm{x}$ a $\mathrm{m}$ i $\mathrm{n}$ e $\mathrm{d}$ : Thirteen females and eight males collected from the body surface of Clinus superciliosus (Linnaeus, 1758). Three females from Clinus cottoides Valenciennes, 1836, three females from Chorisochismus dentex (Pallas, 1769). A single female collected from the body surface of Liza richardsonii
(Smith, 1846) and another from Sarpa salpa (Linnaeus, 1758). Infestation statistics are summarised in Table 1.

De position of voucher specimens: In the collection of the Aquatic Parasitology Research Group, Department of Zoology and Entomology, University of the Free State, Bloemfontein, South Africa (2 males, 5 females, 97/04/07-03); (2 males, 3 females, 98/04/07-07); ( 2 males, 3 females, 98/04/10-02); ( 3 females, 99/01/1802); (3 females, 99/03/22-04). In the collection of the Institute of Parasitology, ASCR, České Budějovice, Czech Republic (1 male, 1 female, PaÚ AVČR 1987) and in the collection of the South African Museum, Cape Town, South Africa (1 male, 1 female, SAM A44115). 
Table 1. Infestation statistics of Caligus mortis Kensley, 1970, from intertidal fish species collected at two localities on the southern coast of South Africa.

\begin{tabular}{|c|c|c|c|c|c|c|c|c|}
\hline \multicolumn{9}{|c|}{ Jeffreys Bay (1997, 1998 and 1999) } \\
\hline Fish host & & $\mathrm{N}$ & $\mathrm{S}(\mathrm{mm})$ & Inf. & $\mathrm{TP}$ & $\mathrm{P}(\%)$ & I & MI \\
\hline Clinus superciliosus (Linnaeus, 1758) & $\mathrm{R}$ & 18 & $86-182(124)$ & 5 & 5 & 27.7 & 1 & 1 \\
\hline Clinus cottoides Valenciennes, 1836 & $\mathrm{R}$ & 3 & $98-107(102)$ & 1 & 1 & 33.3 & 1 & 1 \\
\hline Chorisochismus dentex (Pallas, 1769) & $\mathrm{R}$ & 4 & $143-264(203)$ & 2 & 2 & 50 & 1 & 1 \\
\hline Liza richardsonii (Smith, 1846) & $\mathrm{T}$ & 9 & $110-141(127)$ & 0 & & & & \\
\hline Sarpa salpa (Linnaeus, 1758) & $\mathrm{T}$ & 8 & $49-74(58)$ & 0 & & & & \\
\hline \multicolumn{9}{|c|}{ De Hoop Nature Reserve $(1997,1998$ and 1999) } \\
\hline Clinus superciliosus (Linnaeus, 1758) & $\mathrm{R}$ & 31 & $73-219(129)$ & 7 & 16 & 51.6 & $1-8$ & 2.29 \\
\hline Clinus cottoides Valenciennes, 1836 & $\mathrm{R}$ & 13 & $57-173(90)$ & 2 & 2 & 15.38 & 1 & 1 \\
\hline Chorisochismus dentex (Pallas, 1769) & $\mathrm{R}$ & 1 & 135 & 1 & 1 & 100 & 1 & 1 \\
\hline Liza richardsonii (Smith, 1846) & $\mathrm{T}$ & 171 & $33-210(99)$ & 1 & 1 & 0.58 & 1 & 1 \\
\hline Sarpa salpa (Linnaeus, 1758) & $\mathrm{T}$ & 44 & $107-214(122)$ & 1 & 1 & 2.27 & 1 & 1 \\
\hline Rhabdosargus holubi (Steindachner, 1881) & $\mathrm{T}$ & 25 & $54-121(78)$ & 0 & & & & \\
\hline
\end{tabular}

$\mathrm{N}$ - total number of fish collected; $\mathrm{S}$ - total length of hosts and mean size; Inf. - number of hosts infested; TP - total number of parasites; P - prevalence expressed as a percentage; I - intensity; MI - mean intensity (parasites per host); R - residential tidal pool species; $\mathrm{T}$ - transient tidal pool species

O t h e $\mathrm{r}$ m a t e $\mathrm{r}$ i a 1 : Two females collected from Liza richardsonii and Sarpa salpa, in the collection of the Aquatic Parasitology Research Group, Department of Zoology and Entomology, University of the Free State, Bloemfontein, South Africa.

Vou c her material lo c a lity: Off the south coast, De Hoop Nature Reserve (342'ㅇ, $\left.20^{\circ} 30^{\prime} \mathrm{E}\right)$.

O t h e r 1 o c a 1 i t i e s : Off Jeffreys Bay $\left(34^{\circ} 2.2^{\prime} \mathrm{S}\right.$, $\left.24^{\circ} 56.5^{\prime} \mathrm{E}\right)$.

\section{DISCUSSION}

The most characteristic features of Caligus mortis are the shape of the sternal furca and the two-segmented exopod of leg 4 bearing an armature of I-0; I, I. The majority of Caligus species possess three terminal spines on the exopod of leg 4. Only nine species of the over 300 known species of this genus have been described as bearing two spines at the tip of leg 4 . They are: C. atromaculatus Wilson, 1913, C. centrodonti Baird, 1850, C. distortus Pillai et Natarajan, 1977, C. engraulidis Barnard, 1948, C. labracis Scott, 1902, C. mortis, C. pageti Russell, 1925, C. saucius Dojiri, 1989, and $C$. sensorius Heegaard, 1962. Only five species have a two-segmented exopod of leg 4 with the formula
I-0; I, I. They are: C. centrodonti, C. labracis, C. mortis, C. pageti, and C. sensorius (Dojiri, 1989). Caligus mortis can be distinguished from the other four species by the shape of the sternal furca, and the morphology and relative lengths of the exopodal spines of leg 4, particularly the setiform nature of spine 2 , and spine 1 almost equal in length to the terminal spine.

The male differs from the female in being smaller as well as in the following: Antenna: male antenna with two corrugated patches and well-developed adhesion pads which are absent in the female; terminal segment of male antenna with bifid claw and two strong setae on each side of claw, whereas the terminal segment of the female antenna forms a strongly curved hook, bearing one basal and one marginal seta and two minute hyaline papillae. Maxillule: male maxillule similar to female maxillule, but with a small band of striations on the middle of the process.

Acknowledgements. The authors thank Prof. Ju-Shey Ho of the California State University for his input through personal communication. This study was funded by the marine resource program of the National Research Foundation (NRF) of South Africa.

\section{REFERENCES}

DOJIRI M. 1989: Two species of Caligus (Copepoda: Siphonostomatoida) parasitic on fishes from southern Africa. J. Nat. Hist. 23: 363-374.

HUMES A.G., GOODING R.U. 1964: A method for studying the external anatomy of copepods. Crustaceana 6: 238240 .
KENSLEY B. 1970: A new species of Caligus from South West Africa (Copepoda, Caligidae). Crustaceana 18: 167172.

MARGOLIS L., KABATA Z., PARKER R.R. 1975: Catalogue and synopsis of Caligus, a genus of Copepoda (Crustacea) parasitic on fishes. Bull. Fish. Res. Board Can. 192: 1-117.

Accepted 28 August 2001 